\title{
Assessment of Storage of Medicines at Home using Home Medication Review in Pediatric Population - A Community Based Study
}

\author{
A Ramakrishna Shabaraya ${ }^{1}$, Mohammed Adil Ashraf ${ }^{2}$, Jewel Janice Fernandes 2 , \\ Akhila Ullas ${ }^{2}$, Karol Sara Mathew ${ }^{2}$ \\ ${ }^{1}$ Professor \& Head, Department of Pharmacy Practice, Srinivas College of Pharmacy,Mangalore, Karnataka, \\ India -574143 \\ ${ }^{2}$ Student, Department of Pharmacy Practice, Srinivas College of Pharmacy,Mangalore, Karnataka, India - \\ 574143. \\ Corresponding Author: Mohammed Adil Ashraf
}

\section{ABSTRACT}

People take medicines and vitamins to feel well and to stay well. However, any medicine, including those we buy without a prescription, can cause harm if taken in the wrong way or by the wrong person. That too in case of pediatric population it has to be considered very much.Medicines stored incorrectly at home can pose a health risk. Adult cold medications and antibiotics were the most commonly stored drugs at home, followed by analgesics. The most popular location for storing drugs was the refrigerator (50.6 percent). The majority of people did not read the packaging inserts. Selfmedication was reported by a large percentage of homeowners (53.6\%), and antibiotics recommended by doctors were frequently reused. There was a link between selfmedication and educational attainment, but not with age, sex, marital status, occupation, or insurance type. There is a need for more public awareness and information about the storage and risks of reusing prescription drugs. The study conducted here is a community based prospective study where the paediatric storage of medicines was obtained through home medication review. Out of 150 pediatric participants, it was found that $20.66 \%$ of them stored in box or drawer or bag with lock and 79.33\% without lock. The checking of expiry date was also enquired and in that those who checked expiry date never was $28 \%$, timely $25 \%$ and before administration 47\%.Therefore awareness of storage of medicines and looking
\end{abstract}

into the expiry date of medicines is a less focused area among people.Consumers who use medications in the community should be urged to keep them in a way that preserves the medicine's quality while also protecting the consumer, their family, and visitors to their house.

Key Words: Pediatric storage of medicines, Home medication review, Expiry date of medicines.

\section{INTRODUCTION}

Proper storage of medicines can help us assure that they operate as intended while also reducing the risk of toxicity. The way we store our medicines has an impact on how well they perform.

Approximately $\quad 60,000 \quad$ young children are treated in emergency rooms each year after accidentally ingesting drugs or due to adult dosing errors. It's just as vital to make sure that your children get the correct dosage of medicine as it is to make sure that the medicine is promptly returned to a secure storage area.

Medicines should be kept up and out of sight and reach of small children.

Five simple tips to safe storage at residence and on-the-go:

- Choose a Secure Location: Take a walk around your house to determine the safest location for your medications. The 
place should be high above, out of sight, and out of reach of small children.

- Relock the Safety Cap on a Medicine Container: Always relock the safety cap on a medicine bottle. If the bottle has a turning locking cap, twist it until you hear a click or you can no longer spin it.

- Put Medications Away: After locking the safety cap, it's critical to always place medicines in a safe storage location. Curious youngsters respond quickly, so never leave medicine out on the kitchen counter or at the bedside of a sick child, even if you need to administer it again in a few hours..

- Remind Visitors: When visiting your home, remind family members, houseguests, and other visitors to put medicine-filled purses, bags, or coats up and out of sight.

- If Traveling: If you're staying with family or friends or in a hotel, choose a secure storage location that's out of sight and reach of little children, such as a high cabinet. If you're staying in a hotel, the passcode-protected room safe is a good option for safe storage.

These safe use and storage practises will help parents and caregivers keep children safe from inadvertent medication overdoses this National Safety Month and always.

Consumers should be advised by health care experts and care workers that it is critical to store medicines correctly and in line with any directions on the medicine label.

Medications should be kept in their original containers in a cold, dry, and secure location. Some medicines, such as those that require refrigeration, rely on being stored at the proper temperature to maintain their stability and effectiveness.

Consumers who require assistance in managing their medications may also require assistance in safely storing them, such as away from youngsters and those who are unable to read or interpret labels.
When a patient needs to take their medicines out of the house, the health care provider should provide them with information on how to store and carry their medications safely. For example, drugs that are generally kept in the refrigerator can be placed in a small insulated lunchbox. The consumer should be advised by a health care provider to maintain medicines in their original packaging and to follow the instructions on the label for safe storage. If care workers have questions about transferring a patient's medicine, they should consult a community nurse, pharmacist, or the patient's doctor.

When there is a significant risk of medicine misuse, such as accidental overdose by consumers with dementia or confusion, the service provider (together with additional family members if appropriate/available) may need to take the lead in ensuring that the drugs are properly secured. In such instances, drugs should be kept out of the reach and sight of the consumer while remaining available to those who assist with medication management. Medicines, for example, could be kept in a lockable box in the pantry or kitchen cupboard.

Sharp devices, such as syringes, must be stored with extreme caution.

Consumers are increasingly opting for cytotoxic therapy in the comfort of their own homes. In such instances, the health care professional is responsible for ensuring that the consumer, carers, or other care workers have access to the information they need to ensure everyone in the consumer's household is healthy and safe. Such information should be based on Australian government, state, and territory legislation, and should cover medicine storage at home as well as cytotoxic waste management, including secure cytotoxic waste storage and safety procedures while moving waste containers.

\section{OBJECTIVE}

To determine the storage conditions of medicines in the premises of paediatrics. 


\section{METHODOLOGY}

Study site: In the Dakshina Kannada district of Karnataka, a prospective observational research was conducted.

Study Design: Prospective observational research in the community.

Study period: The research was carried out for six months, from August 2019 to February 2020.

Ethical clearance: The Srinivas Institute of Medical Science and Research Centre's Institutional Ethics Committee (IEC) authorized the study protocol. Mukka, Mangalore (2019/10/28/2 enclosed)

\section{Study criteria:}

\section{Inclusion criteria:}

- Patients under the age of 18 years old including 18 year patients

- Patients using medicine for any illness (current or chronic)

\section{Exclusion criteria:}

- Patients above the age of 18

- Patients who are homeless or do not have a suitable living situation

Source of data: Prescriptions, case files, various test reports, and pharmaceutical formulations that are present at home and used by the paediatric population were used to collect data for this study from the patient's caregivers/parents.

Sampling method: Between August 2019 and February 2020, various residences in various parts of Dakshina Kannada with a paediatric population that met the required requirements were visited. The study included a total of 150 study individuals, which may include more than one subject from the same household who met the selection criteria.

Study method: The data from the patients who are eligible for the study will be collected using a specifically created data collecting form. Demographic information, presenting complaints, medical and drug history, diagnosis, treatment (including dose, frequency, formulation, and duration), and patient progress are all collected. All information will be kept private.

Data Analysis: Microsoft Excel 2010 will be used to analyse the data collected. The filters are used to separate the various categories of the study population so that the study may be scrutinised.

\section{Operation modality:}

Ethical committee approval

Preparation of Data collection form

Community visit and selection of subjects

Signature of informed consent

Data collection

Analyzing data using Microsoft Excel

Presentation of data with tables and graphs 


\section{RESULTS}

The patient/caregiver provides information about where the medications are stored and how they are stored here. Medications are typically kept in the bedroom, living room, refrigerator, kitchen, and bathroom. In this study, 43 (28.6\%) people kept their belongings in their bedrooms, $33(22 \%)$ in their living rooms, $12(8 \%)$ in their refrigerators, $22(14.6 \%)$ in their kitchens, and $9(6 \%)$ in their bathrooms. The majority of people choose to keep their medications in their bedrooms and living rooms. Pediatric drugs are often kept in a lockable box/bag/drawer 31 (20.66 percent) or unlocked 119 percent of the time (79.33 percent). Although it is recommended to keep medicines out of the reach of children, the majority of people store them in an unlocked box, bag, or drawer. The patients/caregivers were also asked for confirmation of the expiration date of the stored medications. Those who never checked the expiration date were 42 percent, those who examined it on time were 38 percent, and those who checked it before administration were 70 percent (47 percent). It was discovered that nearly half of the study population notices the expiration date of stored prescriptions before administering them, while a quarter of the population examines it on time, and a quarter of the population never checks it.

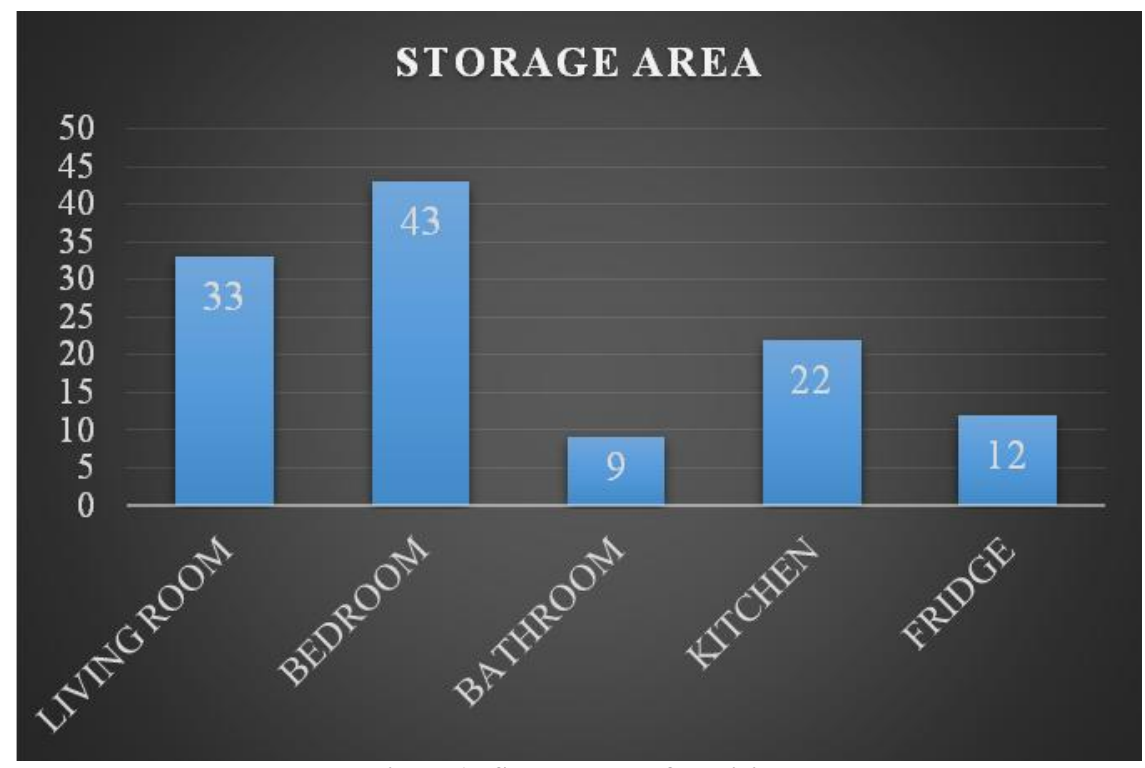

Figure 1 : Storage area of medicine

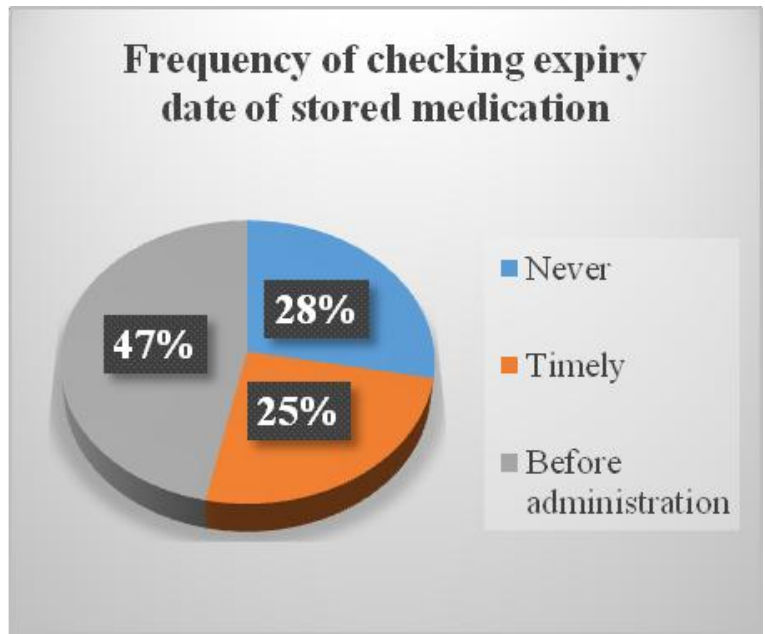

Figure 2 : Frequency of checking expiry date of stored medication
Table 1 : Storage way of pediatric drugs

\begin{tabular}{|l|l|}
\hline STORAGE WAY & $\begin{array}{l}\text { STUDY } \\
\text { PARTICIPANTS }\end{array}$ \\
\hline BOX/BAG/DRAWER LOCKED & $31(20.66 \%)$ \\
\hline $\begin{array}{l}\text { BOX/BAG/DRAWER NOT } \\
\text { LOCKED }\end{array}$ & $119(79.33 \%)$ \\
\hline
\end{tabular}

\section{CONCLUSION}

The adoption of measures aimed at preventing injury is aided by research that identifies the behaviour of families when it comes to the storage of medicines. This study intends to contribute to the adoption of safety measures that include the study's findings to design educational interventions on safe medicine storage at home, hence 
reducing child poisoning from household medications.

The safe storage of medications at home is a major public health concern. According to the findings of our survey, medicines were stored in a hazardous manner in 21.4 percent of homes, putting children at risk of poisoning from household medicines. To reduce the risk of hazardous pharmaceutical storage, health practitioners should enhance teaching about safe medicine storage.

\section{Acknowledgement: None}

\section{Conflict of Interest: None}

\section{Source of Funding: None}

\section{Ethical Approval: Approved}

\section{REFERENCES}

1. Barcelos RS, Santos IS, Matijasevich A, Barros AJ, Barros FC, Franca GV, Silva VL. Falls, cuts and burns in children 0-4 years of age: 2004 Pelotas (Brazil) birth cohort. Cad Saude Publica. 2017;33(2):e00139115.

2. Hyder AA, Sugerman D, Ameratunga S, Callaghan JA. Falls among children in the developing world: a gap in child health burden estimations? Acta Paediatr. 2007;96(10):1394-8.

3. Mowry JB, Spyker DA, Brooks DE, McMillan N, Schauben JL. 2014 annual report of the American Association of Poison Control Centers' National Poison Data System (NPDS): 32nd annual report. Clin Toxicol (Phila). 2015;53(10):9621147.
4. Budnitz DS, Lovegrove MC. The last mile: taking the final steps in preventing pediatric pharmaceutical poisonings. J Pediatr. 2012;160(2):190-2.

5. Kamal NN: Home unintentional non-fatal injury among children under 5 years of age in a rural area, El Minia governorate Egypt , J Community Health 2013, 38(5):873-879.

6. Schmertmann M, Williamson A, Black D, Wilson L. Risk factors for unintentional poisoning in children aged 1-3 years in NSW Australia: a case-control study. BMC Pediatr. 2013;13:88.

7. Halawa EF, Barakat A, Rizk HI, Moawad EM. Epidemiology of non-fatal injuries among Egyptian children: a communitybased cross-sectional survey. BMC Public Health. 2015;15:1248.

8. Ahmed B, Fatmi Z, Siddiqui AR, Sheikh AL. Predictors of unintentional poisoning among children under 5 years of age in Karachi: a matched case-control study. Inj Prev. 2011;17(1):27-32.

9. Paritsis N, Pallis D, Deligeorgis D, Doxiadis S, Phylactou C, Vlachonicolist I. An epidemiological study of the factors influencing poisoning in children aged $0-5$ years. Paediatr Perinat Epidemiol. 1994; 8(1): 79-89.

10. Margonato FB, Thomson Z, Paoliello MMB. Determinantes nas intoxicações medicamentosas agudas na zona urbana de um município do Sul do Brasil. Cad saúde pública. 2008;24(2):333-41.

How to cite this article: A Ramakrishna Shabaraya, Ashraf MA, Fernandes JJ et.al. Assessment of storage of medicines at home using home medication review in pediatric population - a community based study. International Journal of Research and Review. 2021; 8(7): 149-153. DOI: https://doi.org/10. 52403/ijrr.20210720 